\title{
PROJEÇÃo dE CENÁRIOS PARA A PRODUÇÃo DE PESCADO NO ESTADO DO PARÁ E SUAS PERSPECTIVAS MERCADOLÓGICAS
}

\section{PROJECTED SCENARIOS FOR FISH PRODUCTION IN THE PARÁ STATE AND ITS MARKET PERSPECTIVES}

\author{
Marcos Ferreira Brabo ${ }^{1 *}$, Renato Pinheiro Rodrigues ${ }^{1}$, Denys Roberto Corrêa Castro ${ }^{2} \&$ José Milton Barbosa $^{3}$ \\ ${ }^{1}$ Instituto de Estudos Costeiros, Universidade Federal do Pará - UFPA \\ ${ }^{2}$ Instituto Federal de Educação, Ciência e Tecnologia do Pará - IFPA \\ ${ }^{3}$ Departameto de Engenharia de Pesca e Aquicultura, Universidade Federal de Sergipe - UFS \\ *E-mail: marcos.brabo@ hotmail.com
}

RESUMO O estado do Pará conta com condições naturais privilegiadas para a prática das mais diversas modalidades aquícolas, em especial a piscicultura continental. Neste contexto, esta atividade é desenvolvida comercialmente em seu território desde a década de 1980. Porém, a produção atual está muito aquém do potencial estadual, o que o coloca na condição de comprador de pescado oriundo de cativeiro de outros estados brasileiros, como: Maranhão, Rondônia e Mato Grosso. Esta situação é incomoda para a Unidade da Federação que mais forma mão de obra qualificada para atuar na área e deixa no ar a seguinte questão: Qual é a perspectiva de crescimento para a próxima década? O Pará sairá da condição de comprador para vendedor, ou seja, conseguirá atender a demanda do mercado local? Como isso ocorrerá? É o que o presente estudo pretende responder.

Palavras-chave: Amazônia, aquicultura, comércio, pesca, piscicultura.

\begin{abstract}
Pará State has privileged natural conditions for the practice of the most diverse aquaculture modalities, especially fresh water fish farming. In this context, this activity has been developed commercially in its territory since the 1980s. However, the current production is far below the potential of Pará State, which puts it in the condition of buyer of fish from captivity in other Brazilian states, such as: Maranhão, Rondônia and Mato Grosso. This situation is uncomfortable for the Pará State, which trains more qualified labor to work in the area and leaves the question: What is the growth perspective for the next decade? Pará State will leave the condition of buyer to seller, that is, it will be able to meet the demand of the local market? How will this happen? This is what the present study aims to answer.
\end{abstract}

Key words: Amazon, aquaculture, trade, fishery, fish farming.

A produção mundial de pescado alcançou 172,6 milhões de toneladas em 2017, excluindo as plantas aquáticas, com a pesca tendo contribuído com 92,5 milhões de toneladas e a aquicultura com 80,1 milhões de toneladas. Em termos monetários, este total representou US\$ 383,1 bilhões, cerca de US\$ 145,5 bilhões em produtos da pesca e US\$237,5 bilhões da aquicultura (FAO, 2019).

No ano mencionado, o Brasil respondeu por $0,6 \%$ da oferta de pescado no planeta, com 1,2 milhão de toneladas, 704,1 mil toneladas oriundas da pesca e 564,1 mil toneladas advindas da aquicultura. Considerando os valores médios mundiais, a produção brasileira representou cerca de US\$2,7 bilhões, 0,7\% do montante global, sendo US\$ 1,1 bilhão da pesca e US\$ 1,6 bilhão da aquicultura (FAO, 2019; SIDRA, 2020).

Em termos de comércio internacional, as exportações brasileiras foram de 42,4 mil toneladas ou US $\$ 267,8$ milhões e as importações de 402,9 mil toneladas ou US\$1,3 bilhão, um déficit de aproximadamente US\$ 1 
bilhão. Em suma, atualmente, o Brasil participa timidamente da oferta mundial de pescado e importa cerca de dez vezes mais do que exporta, ou seja, está longe de atender a demanda do mercado interno (FAO, 2019; MDIC, 2020).

Neste contexto, o propagado potencial do país para a produção de pescado gerou a estimativa da Organização das Nações Unidas para Alimentação e Agricultura (FAO) de 1,8 milhão de toneladas para o ano de 2030, sendo um milhão de toneladas provenientes da aquicultura, praticamente o dobro da produção oficial de 2017. Na mesma perspectiva, as importações brasileiras chegarão a 969 mil toneladas, enquanto as exportações alcançarão apenas 51 mil toneladas, obviamente a política cambial do país será decisiva para concretizar esta previsão (FAO, 2018).

Agora, a pergunta que não quer calar: como o estado do Pará participará desse mercado? Em estimativas otimistas do extinto Ministério da Pesca e Aquicultura, a produção pesqueira estadual da última década girava em torno de 140 mil toneladas e sua produção aquícola oficial em 2017 foi de 12,2 mil toneladas, o que totaliza aproximadamente 150 mil toneladas (MPA, 2013; SIDRA, 2020). O pescado oriundo do extrativismo atende em sua maior parte ao mercado local, mas também é comercializado em outras Unidades da Federação e até exportado, enquanto a produção da aquicultura é consumida localmente em sua totalidade.

Atualmente, outra diferença entre a pesca e a aquicultura no território paraense está na oferta de produtos. O pescado marinho e dulcícola oriundo do extrativismo oferece uma vasta gama em feiras livres, mercados públicos, supermercados e peixarias, desde peixe inteiro fresco, passando por peixe salgado, até filé de peixe congelado. Na aquicultura, onde a piscicultura continental respondeu por $99,1 \%$ do total produzido, o peixe inteiro fresco é o único produto (SIDRA, 2020).

Neste cenário, os supermercados e peixarias representam exceções, visto que geralmente ofertam filé de tilápia e, raramente, banda desossada e costela de tambaqui congelados, ambos advindos de outros estados. Ainda assim, em relação ao todo, estes produtos e os importados também disponíveis nesses espaços, como a polaca do Alasca, o panga e a merluza, representam uma parcela pequena do mercado paraense se comparado ao que é vendido fresco, em especial nas feiras livres e mercados públicos.

$\mathrm{O}$ incômodo reside na quantidade de peixes redondos, principalmente tambaqui e tambatinga, piabanha e piauçu que vem do Maranhão, de Rondônia e do Mato Grosso para serem vendidos no território paraense, o que eu estimo entre 10 e 20 mil toneladas por ano com base em suas produções e canais de comercialização. Esta situação representa o mais nítido retrato da fragilidade da cadeia produtiva da piscicultura paraense, comprar de um Estado vizinho exatamente o mesmo produto que é o seu carro-chefe no segmento, tambaqui inteiro fresco.

O Brasil importa salmão, bacalhau e outros peixes por não ter condições de capturá-los ou produzi-los através da aquicultura, salvo a exceção do panga, que inclusive já é realidade em alguns estados. Para ilustrar com um exemplo, é como se o Brasil importasse filé de tilápia congelado! Pela estimativa da FAO, as importações crescerão tanto quanto a aquicultura nacional até 2030, mas tenho certeza que não será de tilápia. É uma tendência natural que a expertise brasileira integre cada vez mais nossa pauta de exportação, competindo no mercado global dos grandes importadores, Estados Unidos, Japão, China, Espanha, entre outros.

Diante do exposto e da unanimidade de que a pesca é incapaz de promover um incremento significativo da oferta, venho projetar três cenários possíveis para a produção de pescado no estado do Pará nos próximos dez anos:

Cenário 1) Nada muda em relação ao panorama atual! Passamos mais dez anos com um marco regulatório defasado por falta de interesse e visão dos políticos locais, comprando peixe inteiro fresco oriundo de pisciculturas do Maranhão, de Rondônia e do Mato Grosso. Os problemas com licenciamento ambiental continuam, outorga de direito de uso dos recursos hídricos impraticável, sem perspectivas de acesso à crédito rural e com elevado custo de produção em relação aos concorrentes. Doação de alevinos, escavação de viveiros e feira do pescado

Cenário 2) A piscicultura paraense segue o modelo do estado de Rondônia! Muda o seu marco regulatório e oferece segurança jurídica aos investidores dispostos a criar peixes redondos em viveiros escavados. A produção de cerca de 50 mil toneladas seria absorvida pelo mercado interno e atenderia a outros estados, promovendo um declínio nos atuais maiores produtores, em especial no Maranhão. Este panorama também depende de incentivos fiscais por parte do Governo do Estado, em especial no tocante ao Imposto sobre Circulação de Mercadorias e Serviços (ICMS) e de fomento à produção de grãos.

Cenário 3) A piscicultura paraense segue o modelo do Mato Grosso e do Tocantins! O salto previsto para a produção de peixes redondos no cenário anterior se concretizaria com as medidas supracitadas e a criação 
de tilápia permitiria vislumbrar o posto de maior produtor nacional, pois não haveria a limitação mercadológica do tambaqui. O filé de tilápia aqueceria o parque industrial disponível e o produto ganharia o Brasil e o mundo, gerando uma atração de investimentos imensurável dada as privilegiadas condições hídricas, climáticas e logísticas. Algo entre 100 e 150 mil toneladas, só de tilápia.

Como a resposta sobre o cenário em 2030 só virá daqui a 10 anos, façam suas apostas!

\section{Referências}

FAO - Food and Agriculture Organization of the United Nations (2018). The State of World Fisheries and Aquaculture 2018 - Meeting the sustainable development goals. Roma: FAO yearbook. 2018.

FAO - Food and Agriculture Organization of the United Nations (2019). Fishery and aquaculture statistics 2017. Roma: FAO yearbook. 2019.

MDIC - Ministério da Indústria, Comércio Exterior e Serviços (2020). Disponível em: http://www.mdic.gov.br/ Acesso em: 03 de abril de 2020.

MPA - Ministério da Pesca e Aquicultura (2013). Boletim estatístico de pesca e aquicultura do Brasil 2011. Brasília: República Federativa do Brasil.

SIDRA - Sistema Ibge de Recuperação Automática (2020). Disponível em: <https://sidra.ibge.gov.br/> Acesso em: 03 de abril de 2020. 